\title{
Oncoplastic Breast Surgery Using Spindle Shaped-Partial Mastectomy for Early Breast Cancer in the Upper Quadrant Area*
}

\author{
Yuko Kijima\#, Heiji Yoshinaka, Munetsugu Hirata, Yoshiaki Shinden, Sumiya Ishigami, \\ Akihiro Nakajo, Hideo Arima, Takaaki Arigami, Hiroshi Okumura, Shoji Natsugoe \\ Department of Digestive Surgery, Breast and Thyroid Surgery, Kagoshima University Graduate School of Medical and Dental Sci- \\ ences, Kagoshima, Japan. \\ Email: " ykijima@m3.kufm.kagoshima-u.ac.jp
}

Received February $25^{\text {th }}$, 2013; revised March 27 ${ }^{\text {th }}$, 2013; accepted April $4^{\text {th }}, 2013$

Copyright (c) 2013 Yuko Kijima et al. This is an open access article distributed under the Creative Commons Attribution License, which permits unrestricted use, distribution, and reproduction in any medium, provided the original work is properly cited.

\begin{abstract}
Background: Oncoplastic surgery is becoming more common, however, only several reports have been published in Japan. We report the results of simple oncoplastic surgery for Japanese patients with early breast cancer in the upper quadrant area. Methods: In seven patients with a past history of breast-feeding and ptotic breasts, we performed oncoplastic surgery involving partial mastectomy and the resection of excess skin and parenchymal tissue. Results: None of the patients received a contralateral operation to produce symmetrical breasts. The width of the resected excess skin tissue ranged from 20 to $50 \mathrm{~mm}$, with the mean width being $30 \mathrm{~mm}$, and its length ranged from 50 to 90 , with the mean length being $77 \mathrm{~mm}$. The width of the resected gland tissue ranged from 40 to $65 \mathrm{~mm}$, with the mean width being 53 $\mathrm{mm}$, and its length ranged from 70 to $100 \mathrm{~mm}$, with the mean length being $97 \mathrm{~mm}$. The cosmetic results were excellent. Conclusions: Oncoplastic surgery using spindle shaped-resection was successfully performed in patients with upper quadrant lesions, and the cosmetic results were excellent.
\end{abstract}

Keywords: Breast Cancer; Spindle-Shaped Resection; Breast-Conserving Surgery; Oncoplastic Surgery; Reduction Mammoplasty

\section{Introduction}

Oncoplastic Breast Surgery (OBS), which combine the concepts of oncologic and plastic surgery, are becoming more common, especially in Western countries [1,2]. There are many different oncoplastic surgical techniques, one of which involves careful planning of skin and parenchymal excisions, reshaping of the gland after the parenchymal excisions, and repositioning of the nipple areola complex (NAC) to the center of the breast mound with or without correction of the contralateral breast to achieve better symmetry [3-5]. We have reported that oncoplastic surgery combining partial mastectomy and recentralization of the NAC with/without a contralateral operation produced excellent results in Japanese patients

\footnotetext{
*Conflict of interest statement: We declare that there are no financial relationships or other interests with regard to this manuscript that might be construed as constituting a conflict of interest for any author. Informed consent: Written informed consent from each patient has been received before submission.

${ }^{\#}$ Corresponding author.
}

with ptotic breasts as well as Western women [6-8]. On the other hand, the resection of upper deformities followed by immediate volume replacement using a local flap or a distant autologous graft resulted in good outcomes $[9,10]$.

We herein report our early experiences of oncoplastic surgery involving partial mastectomy and the resection of excess skin tissue without a contralateral operation in six Japanese patients with early breast cancer in the upper quadrant region of their ptotic breasts.

\section{Patients}

From June 2006 to May 2009, seven Japanese patients were diagnosed with early breast cancer and received successful breast conserving surgery without any preoperative systemic therapy. The indications for spindleshaped resection of breast tissue and excess skin tissue were as follows: 1) the patient had ptotic (the nipple level was beneath the inframammary line) or large breasts; 2) 
the cancer lesion was restricted to the upper-outer or upper-inner quadrant; and 3) informed consent was obtained preoperatively after an explanation of the surgical procedure. A digital camera with a resolution of 14.1 megapixels was used, and a blue panel was used as the background. Photographs were taken in four positions with the patient standing on floor marks: facing the camera with their arms down, facing the camera with their arms up, from the left side with their arms up, and from the right side with their arms up.

None of the seven patients who agreed to undergo spindle-shaped partial mastectomy combined with excess skin removal, received preoperative systemic chemo- or endocrine therapy. The mean patient age was 72.4 years (range: 57 - 84). All patients were postmenopausal and had experiences of breast feeding 2 to 4 children, with the mean number of breastfed children being 2.6. The mean size of the tumor was $11.9 \mathrm{~mm}$ (range: 7 - 27) (Table 1). The results of tumor histology are shown in Table 1. Axillary lymph adenectomy was performed for one patient with a clinical diagnosis of T2NOM0. Sentinel lymph node (SLN) biopsy using the radioisotope (RI) method and dye method was performed in the remaining 6 patients, who were preoperatively diagnosed with T1N0M0 tumors. In these six patients, the SLN were intraoperatively revealed to be negative, so axillary con- servation was performed (Table 2).

\section{Surgical Procedure}

\subsection{Design}

The patients were seen by the breast surgeon two days before the surgery so that he could plan the operation, make drawings, and explain the different surgical options to the patient, e.g., other oncoplastic surgical techniques such as immediate volume replacement using a free graft or local flap, which were described previously. For spindle-shaped partial mastectomy and resection of excess skin tissue, the incision lines were drawn with the patient in a standing position after marking the resection area together with a surgical margin of at least $20 \mathrm{~mm}$ with the patient in a supine position (Figure 1).

\subsection{Sentinel Lymph Node Biopsy and Axillary Lymphadenectomy}

In one patient who received axillary lymphadenectomy and two of six patients who underwent SLN biopsy, another incision was made in the axillary area to allow SLN biopsy or axillary lymphadenectomy. In the remaining four patients, the SLN were biopsied via the same incision as was used for the partial mastectomy.

Table 1. Patients' clinical data.

\begin{tabular}{cccccccccccc}
\hline Case & Age & Laterality & Location & Height & Weight & \%IBW & No. of children & Ptosis & Systemic disease Distance to nipple & Tumor size (mm) \\
\hline 1 & 84 & Right & Upper-inner & 141 & 48 & 113 & 4 & Yes & None & 35 & 27 \\
2 & 76 & Left & Upper-inner & 152 & 61 & 108 & 4 & Yes & None & 80 & 12 \\
3 & 63 & Left & Upper-inner & 160 & 80 & 149 & 2 & Yes & Diabetes & 60 & 7 \\
4 & 71 & Left & Upper-inner & 144 & 52 & 112 & 2 & Yes & Arrhythmia & 50 & 12 \\
5 & 57 & Right & Upper-inner & 158 & 70 & 108 & 3 & Yes & None & 60 & 8 \\
6 & 80 & Right & Upper-outer & 157 & 59 & 114 & 2 & Yes & None & 30 & 9 \\
7 & 76 & Left & Upper-outer & 151 & 51 & 101 & 1 & No & None & 90 & 8 \\
\hline
\end{tabular}

Table 2. Surgical findings.

\begin{tabular}{|c|c|c|c|c|c|c|c|c|c|c|c|}
\hline Case & $\begin{array}{c}\text { Surgical margin } \\
\text { (to lateral side) } \\
\text { mm }\end{array}$ & $\begin{array}{c}\text { Surgical } \\
\text { margin } \\
\text { (to nipple) mm }\end{array}$ & $\begin{array}{c}\text { Skin size } \\
\text { (width) } \\
\text { mm }\end{array}$ & $\begin{array}{c}\text { Skin size } \\
\text { (length) } \\
\text { mm }\end{array}$ & $\begin{array}{l}\text { Size of } \\
\text { resected gland } \\
\text { (width) } \mathrm{mm}\end{array}$ & $\begin{array}{l}\text { Size of } \\
\text { resected gland } \\
\text { (length) mm }\end{array}$ & $A x^{*}$ & $\begin{array}{l}\text { Operative } \\
\text { period } \\
\text { (min) }\end{array}$ & $\begin{array}{l}\text { Bleeding } \\
\text { (ml) }\end{array}$ & $\begin{array}{l}\text { Cosmesis } \\
\text { Score } \\
\text { (JBCS) }\end{array}$ & $\begin{array}{c}\text { Cosmesis } \\
\text { Score } \\
\text { (ABNSW) }\end{array}$ \\
\hline 1 & 25 & 40 & 35 & 85 & 80 & 110 & Yes & 90 & 15 & 10 & 11 \\
\hline 2 & 20 & 50 & 20 & 50 & 65 & 110 & $\operatorname{SLN}^{* *}$ & 80 & 5 & 11 & 13 \\
\hline 3 & 20 & 60 & 30 & 90 & 40 & 100 & $\operatorname{SLN}^{* *}$ & 149 & 15 & 10 & 12 \\
\hline 4 & 20 & 20 & 25 & 80 & 50 & 100 & $\operatorname{SLN}^{* *}$ & 131 & 10 & 11 & 13 \\
\hline 5 & 20 & 40 & 25 & 70 & 50 & 70 & $\operatorname{SLN}^{* *}$ & 106 & 5 & 11 & 14 \\
\hline 6 & 25 & 25 & 30 & 80 & 60 & 100 & $\operatorname{SLN}^{* *}$ & 162 & 20 & 11 & 12 \\
\hline 7 & 20 & 40 & 50 & 90 & 50 & 100 & $\mathrm{SLN}^{* *}$ & 92 & 20 & 12 & 15 \\
\hline
\end{tabular}

*Axillary lymphadenectomy; ${ }^{* *}$ Sentinel lymph node biopsy without axillary lymphadenectomy. 
for Early Breast Cancer in the Upper Quadrant Area

\subsection{Spindle Shaped-Partial Mastectomy}

On the day of surgery, both breasts were placed into the operative field to allow evaluation of their symmetry during the operation. The partial mastectomy consisted of the removal of tissue from the breast containing the tumor together with a tumor-free margin of at least $2 \mathrm{~cm}$, including a spindle-shaped area of skin above the tumor and the pectoral fascia below it (Figures 2(a)-(c)).

During the operation, the surgical margins were histologically examined to ensure that they did not include the cancer lesion. It took 30 - 50 minutes to obtain the results from the pathologist, and this time is included in the total operative period shown in Table 1. For both tumor types; i.e., the upper-outer and upper-inner quadrant tumors, SLN biopsy was performed using the same incision as was used for the partial mastectomy.

\subsection{Reconstruction of Defects}

After washing them with saline, the inner and lateral glandular flaps were lined up and sutured together to cover the excision defect (Figures 2(d)-(f)). A closed suction drainage line was placed onto the surface of the pectoralis major muscle and/or the axillary defect in each case.

\subsection{Adjuvant Therapy}

In all patients, pathological margins of over $10 \mathrm{~mm}$ were maintained from the edge of the resected area to the cancer lesion. The treated lesions included both invasive and intraductal lesions. No patient displayed metastatic disease or received postoperative radiotherapy to the remnant gland. Six of them received aromatize inhibitor (1 $\mathrm{mg} /$ day of anastrozol or $2.5 \mathrm{mg} /$ day of letrozol) as an adjuvant hormone therapy.

\section{Cosmetic Evaluation}

The cosmetic assessment after the breast-conserving therapy was performed according to the method reported by Sawai's group, which was supported by the Japanese Breast Cancer Society [11]. This assessment contains eight items: 1) breast size; 2) breast shape; 3) wound scar; 4) softness of the breast; 5) shape and size of the nipple-areola complex; 6) color of the nipple-areola complex; 7) level of the nipple (difference in distance from the suprasternal notch between the bilateral nipples); and 8) the lowest point of the breast (difference between the bilateral breasts). The cosmetic outcome was evaluated as excellent when the total score was 12 points, good when it was 9 to 11 , fair when it was 5 to 8 , and poor when it was 0 to 4 .

Breast shape was also subjectively assessed by two of the authors and scored using the ABNSW system reported by Yamashita et al. [12]. The ABNSW contains five items: asymmetry (A), breast shape (B), nipple deformation $(\mathrm{N})$, skin condition $(\mathrm{S})$, and wound scar $(\mathrm{W})$. The score in each category is graded as follows: 3-excellent: at first sight, there was no visible difference between the breasts; 2-good: there were few differences between the bilateral breasts and these were only apparent from close observation; 1-fair: there were marked differences between the bilateral breasts from a distance; 0-poor: there were severe, ugly differences between the bilateral breasts. We scored all five items from 0 to 3 to produce the total score. The cosmetic outcome was evaluated as excellent when the total score was 15 points, good

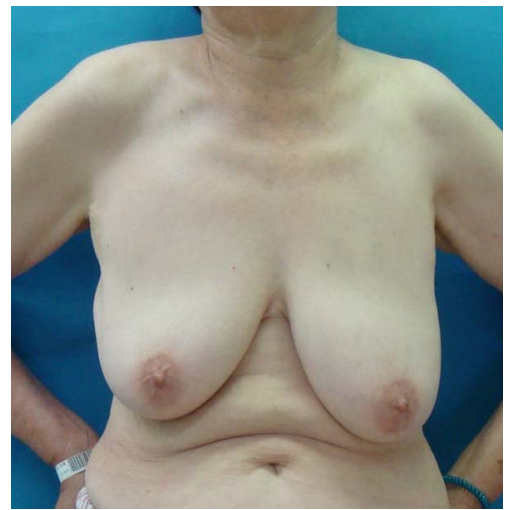

(a)

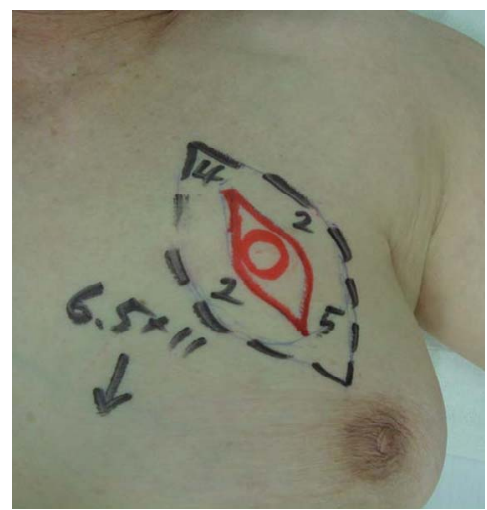

(b)

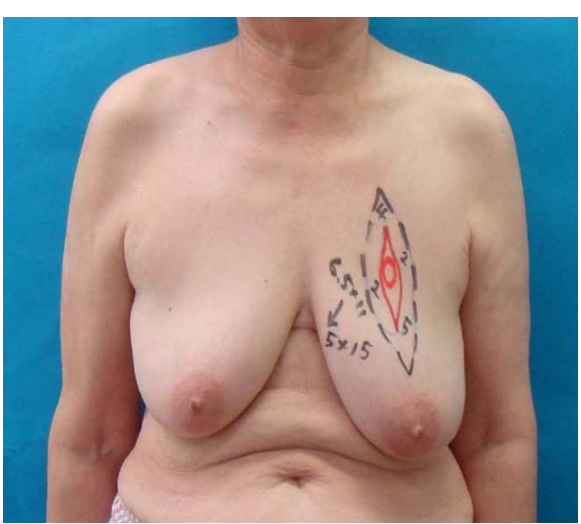

(c)

Figure 1. Case 1, a 76-year-old patient with a T1 tumor in the upper-inner quadrant of her left breast. Preoperative findings. (a) Bilateral ptotic breasts with the nipple-areola complex (NAC) beneath the inframammary line; (b) Lesions were detected by ultrasonography with the patient in a supine position (red circle). Two cm lateral surgical margins were maintained. A spindle shaped resection area, measuring $6.5 \times 11 \mathrm{~cm}$, was marked using a dotted black line. The spindle shaped incision line was drawn in red; (c) With the patient in a standing position, the spindle shaped resected area and skin island became rectangular and measured $5 \times 15 \mathrm{~cm}$. 


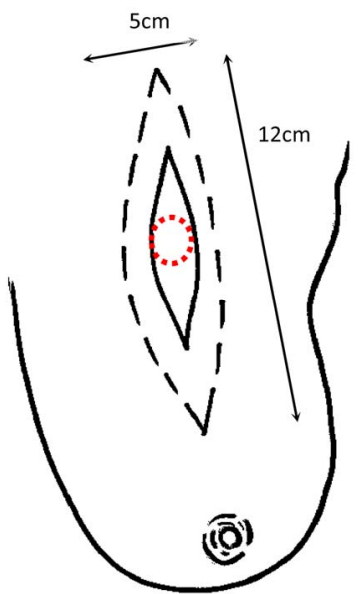

(a)

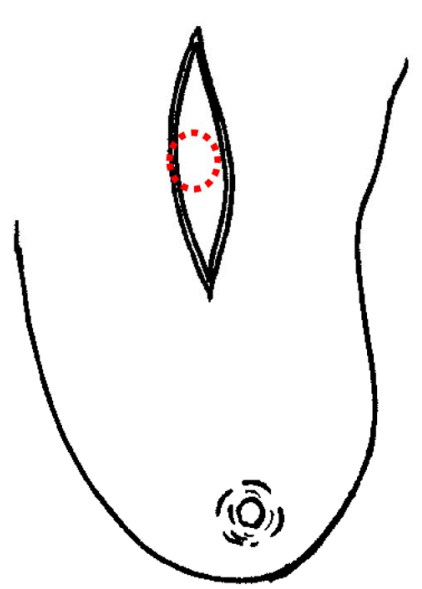

(b)

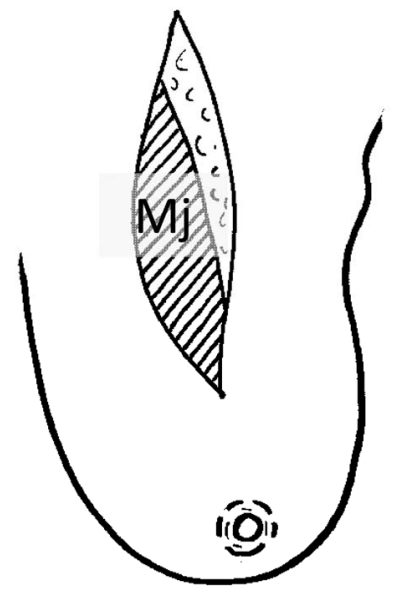

(c)

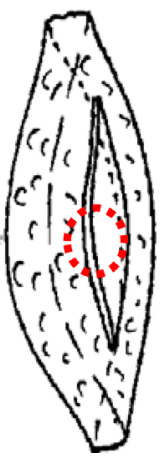

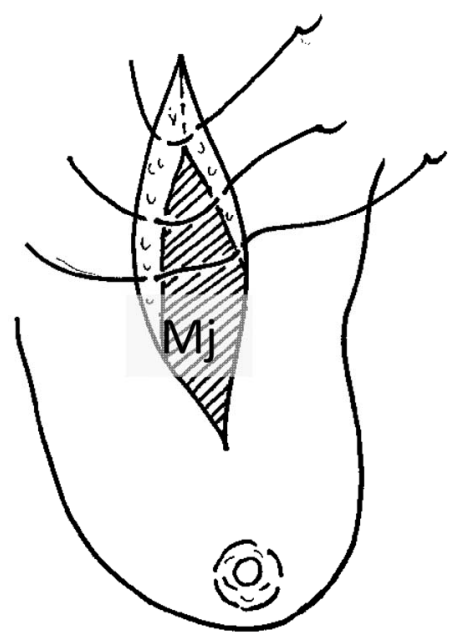

(d)

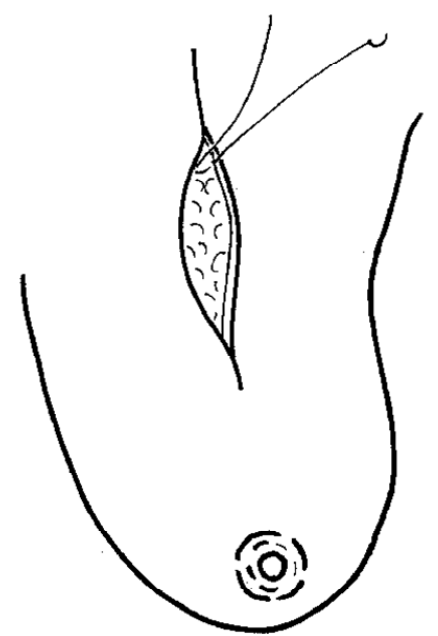

(e)

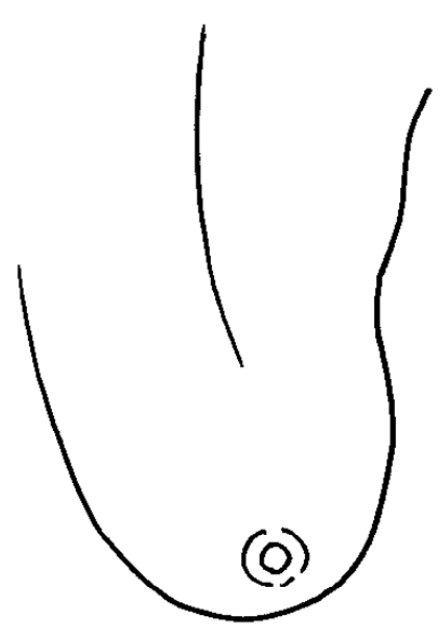

(f)

Figure 2. (a) Preoperative marking. The incision line and surgical margin of the gland were drawn as a black line and dotted line, respectively; (b) A spindle shaped area of skin was also removed; (c) A spindle shaped area of columnar tissue was resected together with the fascia of the pectoral major muscle; (d) Medial and lateral glandular flaps were sutured using 3-0 vicryl sutures; (e) and (f) Subcutaneous 4-0 PDS sutures were also added. Mj: Pectoral major muscle.

when it was 11 to 14 , fair when it was 6 to 10 , and poor when it was 0 to 5 .

\section{Results}

The patients' clinical data are shown in Table 1. No additional resections due to a positive margin were necessary. The total operative period ranged from 92 to 162 minutes, with the mean period being 116 minutes. The suction drainage period required for each breast ranged from 3 to 5 days postoperatively.

The postoperative observation period ranged from 5 to 60 months (median: 20 months). There were no complications in any of the treated breasts, and no local or distant recurrence was seen in any case (Figures 3 and 4).

In the objective assessment (Japanese Breast Cancer Society), the total cosmetic score ranged from 10 to 12 ; the score was 12 in one patient, 11 in four, and 10 in two patients. In the subjective assessment (ABNSW), the total cosmetic scores ranged from 12 to 15 ; the score was 15 in one patient, 14 in one, 13 in two, 12 in two, and 11 in one patient. The cosmetic outcomes were excellent or good in both cosmetic assessments.

\section{Discussion}

The final cosmetic result of breast conserving therapy is dependent on many factors, including tumor size, tumor site, breast volume, the extent of surgery, chemotherapy, radiotherapy, hormone therapy, and age [13-17]. Tumor size in relation to breast size is one of the most important factors to consider when attempting obtaining a cosmetically favorable result. Performing a resection that is wide enough to obtain optimal oncologic control often requires 


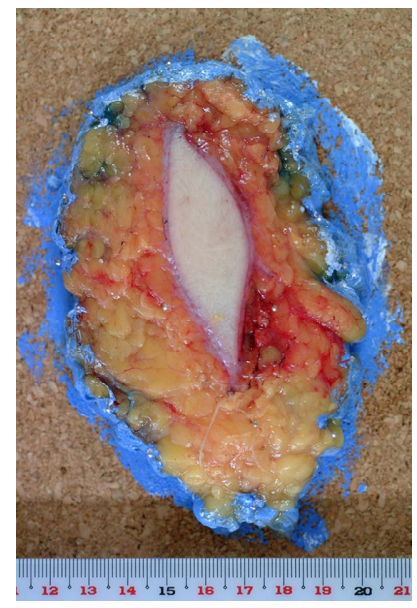

(a)

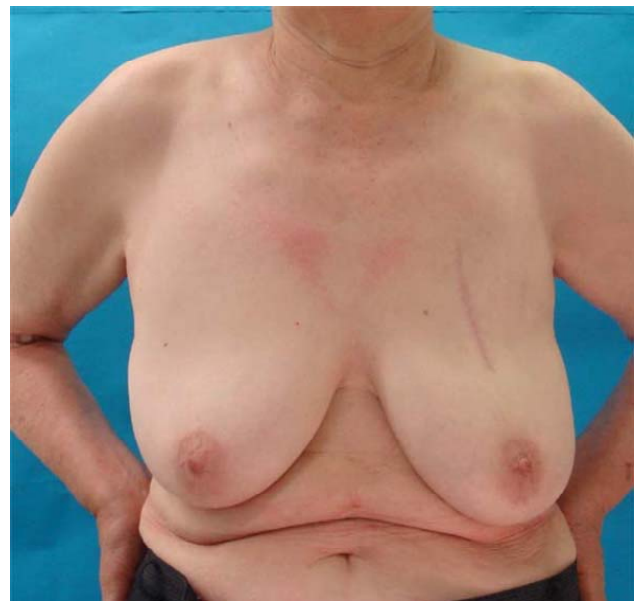

(b)

Figure 3. (a) The resected spindle-shaped area of columnar tissue and excess skin; (b) One-year postoperative findings (Case 1).

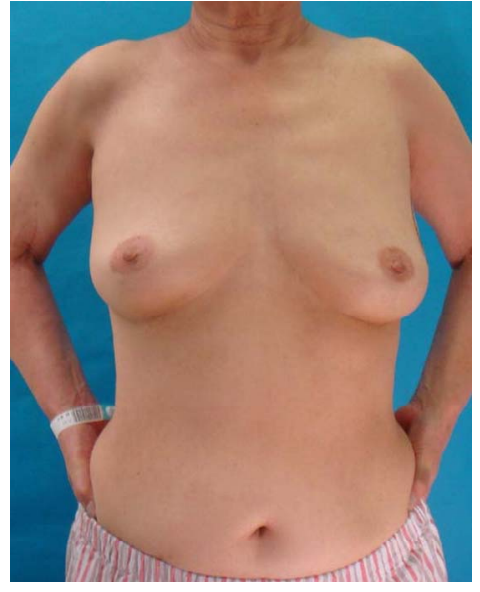

(a)

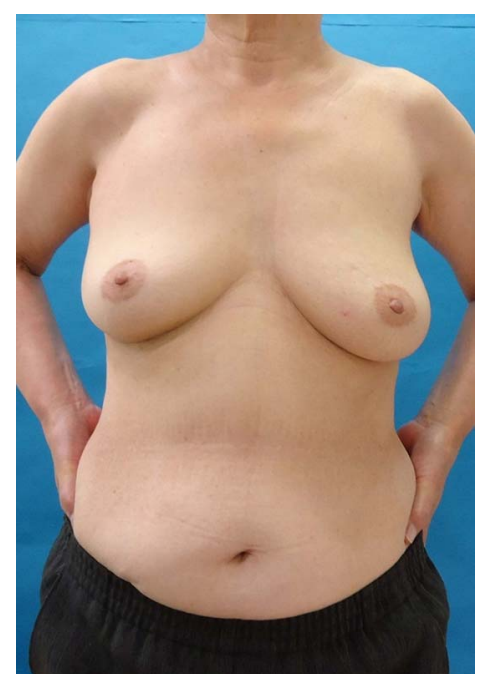

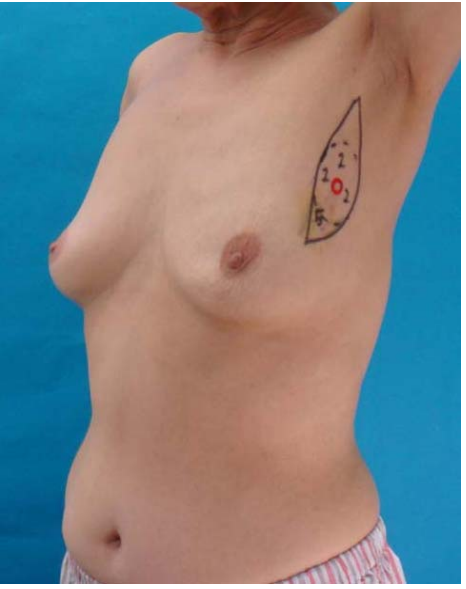

(b)

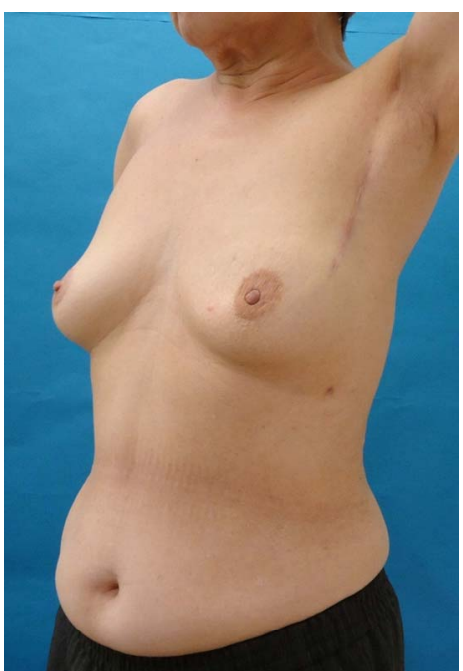

(c)

Figure 4. Case 6, a 76-year-old patient with a T1 tumor in the upper-outer quadrant of her left breast. Preoperative and postoperative findings (a) and (b) Preoperative findings after marking. A spindle shaped area of skin and gland tissue with a surgical margin of least $2 \mathrm{~cm}$ was drawn as a black line; (c) One-year postoperative findings. 
removing so much breast tissue that it will leave a deformed breast or a large discrepancy compared with the contralateral breast. Quadrantectomy increases the risk of a poor aesthetic result if no partial breast reconstruction is performed [18-20]. The impact of tumor surgery on cosmesis in BCT has also been emphasized by leading surgeons: surgical technique may influence the aesthetic outcome to a greater extent than radiation effects [21].

Postquadrantectomy deformities include localized defects in skin and glandular tissue, distortion and/or dislocation of the areola, and retraction of the breast tissue. Perhaps the most prominent and frequent failure in achieving a good aesthetic outcome is due to a lack of breast symmetry [22]. Surgical techniques used to address the conflicts between oncological and cosmetic results, including both total and partial mastectomy, can be classed under the general term of oncoplastic surgery, which is a new surgical approach that allows wide excision but prevents breast deformities by reconstructing large resection defects immediately [13]. Several oncoplastic surgical procedures have been discussed in previous reports. Hoffmann classified all breast surgeries into 12 subgroups according to a two-type, six-tier classification system comprising 12 main categories [23]. In breast conserving surgery, ranging from simple excision up to quadrantectomy, defect repair without tissue mobilization is regarded as grade 1 complexity, and complex oncoplastic or reconstructive breast cancer procedures involving pedicled or free distant flap reconstruction and, where indicated, microvascular anastomosis for defect coverage are regarded as grade 6. Our procedure, a spindle shaped partial mastectomy in which excess gland and skin tissue are removed, is regarded to be of grade 1 complexity according to their classification. In fact, it is easier than other oncoplastic breast surgical techniques that we described previously, such as volume replacement or reduction type breast surgery.

Masetti et al. outlined several important aspects of oncoplastic breast surgery procedures: first, careful planning of skin incisions and parenchymal excisions must be made, following the templates used for reduction mammaplasty and mastopexy; second, the gland must be reshaped after the parenchymal excision; third, the nipple-areola complex must be repositioned in the center of the breast mound; and fourth, the symmetry of the contralateral breast must be corrected. Another researcher highlighted four integral features of oncoplastic surgery [3]. All of these require planning with respect to the placement and closure of wounds and careful assessment of the oncological need and aesthetic aim [24].

We reported good results for immediate volume replacement surgery using a free dermal fat graft for the treatment of upper-inner lesions $[10,25,26]$. This is thought to be sufficient for slim ladies with non-ptotic, small breasts, e.g., average Japanese ladies. It is easy to perform; however, there are some disadvantages to this procedure, for example, it is difficult to maintain softness, and an additional scar is made at the donor site. In such cases with breast cancers on upper quadrant lesion on ptotic breasts, OBS combining with partial mastectomy and reduction type mammoplasty brought excellent cosmetic results, although surgical techniques might be more complicated than former ones [27].

We performed oncoplastic surgery involving spindleshaped partial mastectomy and excess skin removal in several older ladies in this series, and all procedures were successful. We produced satisfactory cosmetic results, and the observation period was thought to be sufficient. One drawback of this technique is the length of the scar it leaves. In particular, hypertrophic scars in the upperinner quadrant area will reduce cosmesis. In this series, the patients' satisfaction was high because the symmetry of the bilateral breasts was well maintained, especially in the position of NAC, and the softness of the whole breast was also retained by avoiding tissue mobilization to repair the breast defects.

The number of cases in this paper was not so large, and the follow-up period was short; however, we have revealed that oncoplastic surgery using spindle shapedpartial mastectomy combined with the removal of excess skin for patients with upper quadrant lesions in ptotic or large breasts produced excellent cosmetic results via a simple technique. This simple oncoplastic technique is an excellent procedure that yields very satisfactory cosmetic results, and it should be considered a suitable therapeutic option.

\section{Conclusion}

OBS involving spindle-shaped partial mastectomy combined with excess skin removal was successfully performed and is expected to become more popular for the treatment of aging patients.

\section{REFERENCES}

[1] W. P. Audretsch, M. Rezai, C. Kolotas, N. Zamboglou, T. Schnabel and H. Bojar, “Onco-Plastic Surgery: 'Target' Volume Reduction (BCT-Mastopexy), Lumpectomy Reconstruction (BCT-Reconstruction) and Flap-Supported Operability in Breast Cancer,” Proceeding 2nd European Congress on Senology, Vienna, 2-6 October 1994, pp. 139-157.

[2] W. P. Audretsch, M. Rezai, C. Kolotas, N. Zamboglou, T. Schnabel and H. Bojar, "Tumor-Specific Immediate Reconstruction (TSIR) in Breast Cancer Patients,” Perspectives in Plastic Surgery, Vol. 11, 1998, pp. 71-106.

[3] R. Masetti, P. G. Pirulli, S. Magno, G. Francesch, F. Chi- 
esa and A. Antinori, "Oncoplastic Techniques in the Conservative Surgical Treatment of Breast Cancer,” Breast cancer, Vol. 7, No. 4, 2000, pp. 276-280. doi:10.1007/BF02966389

[4] Y. Kijima, H. Yoshinaka, Y. Funasako, S. Natsugoe and T. Aikou, “Oncoplastic Surgery after Mammary Reduction and Mastopexy for Bilateral Breast Cancer Lesions: Reports of a Case,” Surgery Today, Vol. 38, No. 4, 2008, pp. 335-339. doi:10.1007/s00595-007-3628-z

[5] H. Zaha, O. Hakazu, M. Watanabe and M. Higa, "BreastConserving Surgery Using Reduction Mammoplasty," Japanese Journal of Breast Cancer, Vol. 23, 2008, pp. 211-215.

[6] Y. Kijima, H. Yoshinaka, M. Hirata, T. Mizoguchi, S. Ishigami, A. Nakajo, H. Arima, S. Ueno and S. Natsugoe, "Oncoplastic Surgery in a Japanese Patient with Breast Cancer in the Lower Inner Quadrant Area: Partial Mastectomy Using Horizontal Reduction Mammoplasty,” Breast Cancer, 2010.

[7] Y. Kijima, H. Yoshinaka, M. Hirata, K. Kaneko, M. Hirata, T. Mizoguchi, S. Ishigami, H. Arima, A. Nakajo, S. Ueno and S. Natsugoe, "Oncoplastic Surgery Combining Partial Mastectomy with Breast Reconstruction Using the Free Nipple-Areola Graft Technique for a Japanese Patient with DCIS in a Ptotic Breast: A Case Report,” Surgery Today, Vol. 41, No. 3, 2011, pp. 390-395. doi:10.1007/s00595-010-4294-0

[8] Y. Kijima, H. Yoshinaka, H. Munetsugu, T. Mizoguchi, S. Ishigami, A. Nakajo, H. Arima, S. Ueno and S. Natsugoe, "Oncoplastic Surgery for Japanese Patients with Breast Cancer of the Lower Pole," Surgery Today, Vol. 41, No. 10, 2011, pp. 1461-1465. doi:10.1007/s00595-011-4490-6

[9] Y. Kijima, H. Yoshinaka, Y. Funasako, K. Kaneko, M. Hirata, S. Ishigami and S. Natsugoe, "Immediate Reconstruction Using Thoracodorsal Adipofascial Flap after Partial Mastectomy,” Breast, Vol. 18, No. 2, 2009, pp. 126-129. doi:10.1016/j.breast.2009.02.006

[10] Y. Kijima, H. Yoshinaka, T. Owaki and T. Aikou, "Early Experience of Immediate Reconstruction Using Autologous Free Dermal Fat Graft after Breast Conservational Surgery," Journal of Plastic, Reconstructive \& Aesthetic Surgery, Vol. 60, No. 5, 2007, pp. 495-502. doi:10.1016/j.bjps.2006.06.004

[11] Japanese Breast Cancer Society, "Cosmetic Assessment after Breast Conserving Surgery,” The 12th Annual Meeting of the Japanese Breast Cancer Society, 2004, pp. 107-109.

[12] K. Yamashita, “Cosmetic Assessment,” Journal of Japan Society for Endoscopic Surgery, Vol. 10, No. 2, 2004, pp. 165-170.

[13] K. B. Clough, J. Cuminet, A. Fitoussi, C. Nos and V. Mosseri, "Cosmetic Sequelae after Conservative Treatment for Breast Cancer: Classification and Results of Surgical Correction,” Annals of Plastic Surgery, Vol. 41, No. 5, 1998, pp. 471-481. doi:10.1097/00000637-199811000-00004

[14] J. Bostwick III, C. Paletta, C. R. Hartramph, “Conservative Treatment for Breast Cancer: Complications Requir- ing Reconstructive Surgery,” Annals of Surgery, Vol. 203, No. 5, 1986, pp. 481-490. doi:10.1097/00000658-198605000-00006

[15] J. Y. Petit and M. Rietjens, "Deormities Following Tumorectomy and Partial Mastectomy,” In: B Noon, Ed., Plastic and Reconstructive Surgery of the Breast, Marcel Decker, Philadelphia, 1991.

[16] K. B. Clough, C. Nos, R. J. Salmon, M. Soussaline and J. C. Durand, "Conservative Treatment of Breast Cancers by Mammaplasty and Irradiation: A New Approach to Lower Quadrant Tumors,” Plastic \& Reconstructive Surgery, Vol. 96, No. 2, 1995, pp. 363-370. doi:10.1097/00006534-199508000-00015

[17] M. Noguchi, Y. Saito, Y. Mizukami, A. Nonomura, N. Ohta, N. Koyasaki, et al., "Breast Deformity, Its Correction, and Assessment of Breast Conserving Surgery," Breast Cancer Research and Treatment, Vol. 18, No. 2, 1991, pp. 111-118. doi:10.1007/BF01980973

[18] P. Berrino, E. Campora and P. Santi, "Postquadrantectomy Breast Deformities: Classification and Techniques of Surgical Correction,” Plastic \& Reconstructive Surgery, Vol. 79, No. 4, 1987, pp. 567-572. doi:10.1097/00006534-198704000-00010

[19] D. Clarke, A. Martinez and R. S. Cox, “Analysis of Cosmetic Results and Complications in Patients with Stage I and II Breast Cancer Treated with Biopsy and Irradiation," International Journal of Radiation Oncology, Biology, Physics, Vol. 9, No. 12, 1983, pp. 1807-1813. doi:10.1016/0360-3016(83)90348-6

[20] J. R. Harris, M. B. Levene, G. Svensson and S. Hellman, "Analysis of Cosmetic Results Following Primary Radiation Therapy for Stage I and II Carcinoma of the Breast," International Journal of Radiation Oncology Biology Physics, Vol. 5, No. 2, 1979, pp. 257-261. doi:10.1016/0360-3016(79)90729-6

[21] W. E. Matory Jr., M. Wertheimer, T. J. Fitzgerald, R. L. Walton, S. Love and W. E. Matory, "Aesthetic Results Following Partial Mastectomy and Radiation Therapy," Plastic \& Reconstructive Surgery, Vol. 85, No. 5, 1990, pp. 739-746. doi:10.1097/00006534-199005000-00014

[22] A. Grisotti, "Immediate Reconstruction after Partial Mastectomy," Operative Techniques in Plastic and Reconstructive Surgery, Vol. 1, No. 1, 1994, pp. 1-12. doi:10.1016/S1071-0949(10)80013-7

[23] J. Hoffmann and D. Wallwiener, "Classifying Breast Cancer Surgery: A Novel, Complexity-Based System for Oncological, Oncoplastic and Reconstructive Procedures, and Proof of Principle by Analysis of 1225 Operations in 1166 Patients,” BMC Cancer, Vol. 9, 2009, p. 108. doi:10.1186/1471-2407-9-108

[24] A. D. Baildam, "Oncoplastic Surgery of the Breast,” British Journal of Surgery, Vol. 89, No. 5, 2002, pp. 532-533. doi:10.1046/j.1365-2168.2002.02077.X

[25] Y. Kijima, H. Yoshinaka, Y. Funasako, K. Kaneko, M. Hirata, T. Mizoguchi, S. Ishigami, H. Arima, A. Nakajo, S. Ueno and S. Natsugoe, "Immediate Breast Reconstruction Using Autologous Free Dermal Fat Graft Provides Better Cosmetic Results for Patients with Upper Inner 
Cancer Lesion,” Surgery Today, Vol. 41, No. 4, 2011, pp. 477-489. doi:10.1007/s00595-010-4307-Z

[26] Y. Kijima, H. Yoshinaka, M. Hirata, Y. Umekita, M. Sohda, C. Koriyama, et al., "Clinical and Pathological Evaluation of Free Dermal Fat Graft after Breast Conservative Surgery and Immediate Breast Reconstruction," Surgery, Vol. 151, No. 3, 2012, pp. 444-455. doi:10.1016/j.surg.2011.07.031

[27] Y. Kijima, H. Yoshinaka, M. Hirata, A. Nakajo, H. Arima, S. Ishigami, et al., "Oncoplastic Breast Surgery Combining Periareolar Mammoplasty with Volume Displacement Using a Crescent Shaped Cutaneous Flap for Early Breast Cancer in the Upper Quadrant Area,” Surgery Today, in Press. 